\title{
Different Marketing Strategies Between Starbucks and Luckin Coffee and the Impact of the Epidemic
}

\author{
Siyu Wang ${ }^{1}$ \\ ${ }^{1}$ Dulwich International High School Suzhou, Suzhou, China, 215000 \\ Corresponding author. Email: 1963515817@qq.com

\begin{abstract}
COVID-19 spreads and causes a significant negative impact on the global beverage industry. The global coffee market is estimated to be worth $\$ 102.02$ billion in 2020 with a projected compound annual growth rate of $4.28 \%$ for the 2021-2026 forecast period. This paper studies the different marketing strategies of Starbucks and Luckin Coffee in the coffee industry and then discusses the impact of different periods of the epidemic on Starbucks to different degrees through data, as well as the countermeasures taken by Starbucks.
\end{abstract}

Keywords: Marketing Strategies, Starbucks, Luckin Coffee, COVID-19

\section{INTRODUCTION}

Coffee is a drink made from coffee beans that have been roasted and ground. Although the annual coffee consumption in China is only 200,000 tons, the per capita coffee consumption is increasing at a rate of $30 \%$, and China is expected to become the world's largest coffee consumer with the greatest potential.[1] Therefore, many enterprises are very optimistic about the coffee market in China, such as Starbucks.

Figure 1 shows the size of the global coffee market in different colors. Europe and North America appear green, where people rely on coffee. While China and the Continent appear yellow, which can be explained by the continued expansion of coffee markets in these regions. However, South America and Africa in red indicate that coffee is not common enough in those regions. According to the world coffee consumption situation, coffee enterprises such as Starbucks can choose the regions to set up stores to expand the market and increase the sales of coffee and related products.

Starbucks is an American coffee chain company founded in 1971. Its retail products include more than 30 kinds of coffee beans, hand-made coffee, coffee drinks, snacks, cups and other commodities. Starbucks has also seen the development of the Chinese coffee market, and has shifted its focus on overseas markets to expand in China. The number of new stores opened in China is increasing every year, and Starbucks is confident in its presence and operations in China. Nowadays, Starbucks has more than 32,000 stores and more than 400,000 employees in 82 markets around the world.[2] It entered the Chinese market in January 1999 and China has become Starbucks' fastest growing and largest overseas market. 


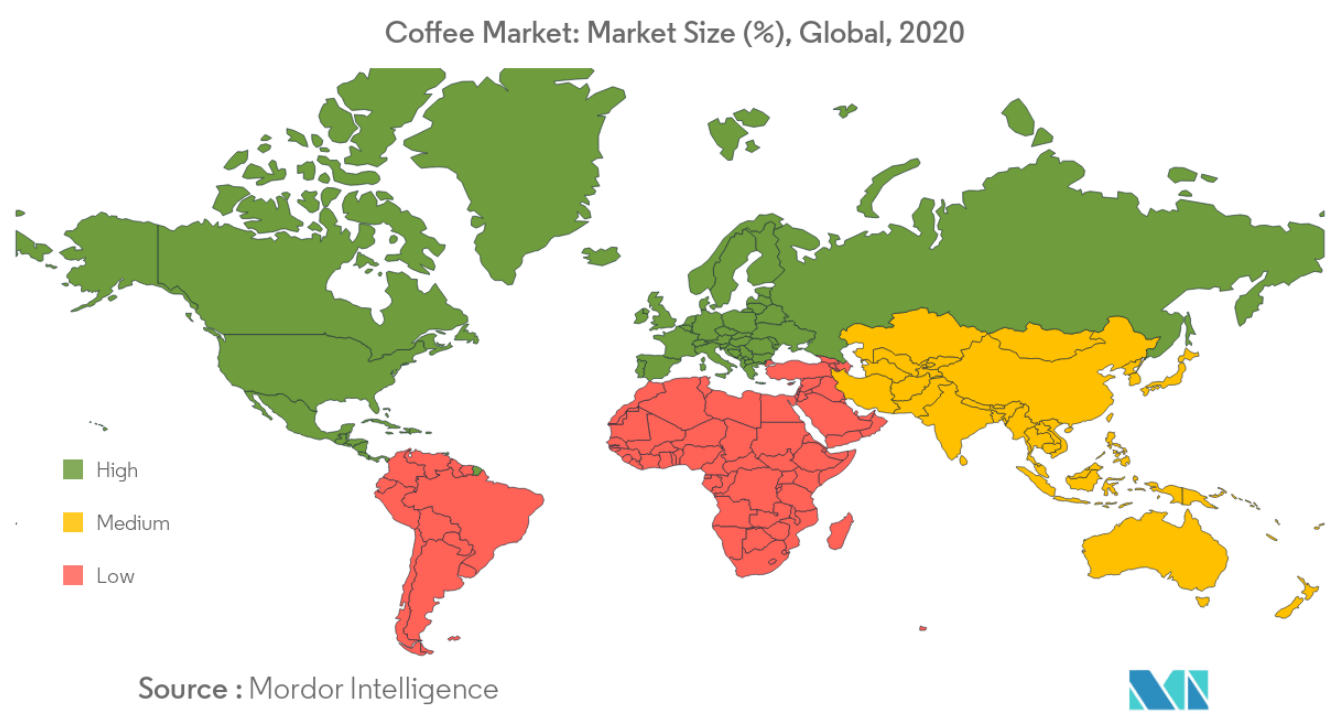

Figure 1: Coffee Market, 2020

Luckin Coffee is the largest coffee chain brand in China and is committed to building a world-class coffee brand originating in China. Its first store opened in October 2017, and the number of stores reached 4,500 by the end of 2019.[3]That's close to the number of stores Starbucks has in China.

\section{STARBUCKS' MARKETING STRATEGY}

\subsection{Product Differentiation}

The price of Starbucks cakes and other products is close to the market price, but the taste of these products is higher than that of other brands. While the price of coffee and other drinks is slightly higher. When the profit from selling coffee is considerable, the sale of other products will not be the focus, which creates a relaxed consumption environment for consumers. According to the survey, Starbucks consumers mostly buy coffee or snacks with it because the expense of snacks is not a great burden to consumers. At the same time, Starbucks reasonably determines the prices of different products in its product line to maximize profits. For example, during the Christmas season, new drinks, snacks, etc., will be introduced, and most of these products will only be sold during the holiday. When it enters the Chinese market, it also launches suitable products and in-store designs based on Chinese traditional culture, such as moon cakes.

\subsection{Membership Cards}

Starbucks China will launch membership cards with different themes every quarter, with different prices (including recharge cards, discount cards, etc.). The shape and appearance of membership cards are very popular with consumers and encourage consumers to buy and consume. The membership card has three levels: Silver Level, Green Level and Gold Level. Started as a Silver Level (with five coupons). Spend more than 50 yuan will get one star and collect more than 5 stars will upgrade level. Different levels get different discounts. In addition, the membership card has gradually changed from a physical card to an electronic card, which is convenient to use. Starbucks APP will remind the discount coupons in the membership card every month, thus increasing customer loyalty and reputation.

\subsection{Starbucks Positioning}

Starbucks positions its products as "an affordable luxury for most people". The main consumer groups are people who have higher income and pay attention to the taste. Therefore, when Starbucks entered the Chinese market, its stores were mostly located in the main streets with high population flow and high per capita consumption level. Besides, Starbucks is committed to becoming a third space independent of home and office, so as to provide consumers with a more fashionable and warm place. For example, sensory control. The flavor of Starbucks is the aroma of pure coffee beans. The strict rules such as perfume and food flavor create a high-end atmosphere.

\subsection{Sales Model}

Starbucks entered China through a combination of licensing and joint ventures. Gradually, through stock acquisition, Starbucks acquired the right to operate in many places in China, and began direct business expansion. Since 2005, Starbucks in Xi 'an, Chengdu, Chongqing and other second-tier cities continue to establish their own direct-sale stores. 


\subsection{Compared with Luckin Coffee}

Unlike Starbucks, Luckin sells its coffee at very low prices and directly competes with Starbucks. This is conducive to Luckin Coffee quickly establish a "low price and high quality" brand image. Starbucks focuses on the experience of "the third space", while Luckin focuses on the infinite scene to meet the needs of consumers in a more efficient and convenient way. This concept also allows Luckin to save a lot of money in labor costs, store design and other aspects. At the same time, Luckin offers a large number of discount coupons, where new users can directly get a 100 yuan credit and get more discounts for completing tasks and inviting new people. Free drinks bring a lot of traffic, which also reflects the success of the fission marketing of Luckin Coffee. In addition, the pattern of Luckin coffee takes blue as the base, and the white part in the middle is a deer. This simple design also highlights its commercialization. Different from Starbucks, it also invests a lot of money in advertising and selects stars to endorse products in line with its brand image, thus entering the public eye. At the same time, Luckin Coffee uses the slogan of "Little Blue Cup, Who Doesn't Love" to attract the attention and thinking of consumers.

\section{THE IMPACT OF COVID-19 ON STARBUCKS}

At the end of 2019, COVID-19 first appeared in Wuhan and rapidly developed into a global pandemic. Both the United States and China have taken measures to control the outbreak. The global market of Starbucks has been affected to varying degrees and may continue to have a certain impact on the financial situation and store plan of Starbucks. The impact of COVID-19 on
Starbucks' business in the Americas is about $\$ 450$ million.[4]

As the end of April 2020, COVID-19's impact on Starbucks revenue is estimated to be approximately $\$ 915$ million due to temporary closures, limited distribution channels, shortened operating hours, and so on. This represents $80 \%$ of the traffic caused by revenue declines, significantly higher than the $50 \%$ variable traffic companies typically observe and reflects both employee and long-term investment to weather the crisis. [4]

In the early days of the outbreak, Starbucks was not significantly affected. For the first quarter of 2020, consolidated net revenue was $\$ 7.1$ billion, up $7 \%$ year on year. [5]Figures for the second quarter show consolidated net revenue of $\$ 6$ billion, down $5 \%$ year over year due to the adverse impact of COVID-19. [6] Then, the negative impact in the third quarter was exacerbated by the outbreak as previously expected. Consolidated net income was $\$ 4.2$ billion, down $38 \%$ from the same period last year. [7]The impact of COVID-19 eased significantly in the fourth quarter as the economy continued to recover. At the end of the fourth quarter of 2020, stores in the U.S. and China accounted for $61 \%$ of the company's global portfolio with 15,337 and 4,706 stores respectively. Consolidated net revenue was $\$ 6.2$ billion, down $8 \%$ from the previous year. [8]About $\$ 1.2$ billion in lost sales compared to what the company had expected before the outbreak, including the impact of improved operations, reduced hours, reduced foot traffic and temporary store closures. Although Starbucks China's revenue in the first quarter of 2021 was successfully increased due to the good control of the epidemic, consolidated net income was the US $\$ 6.7$ billion, down $5 \%$ from the previous year.[9]

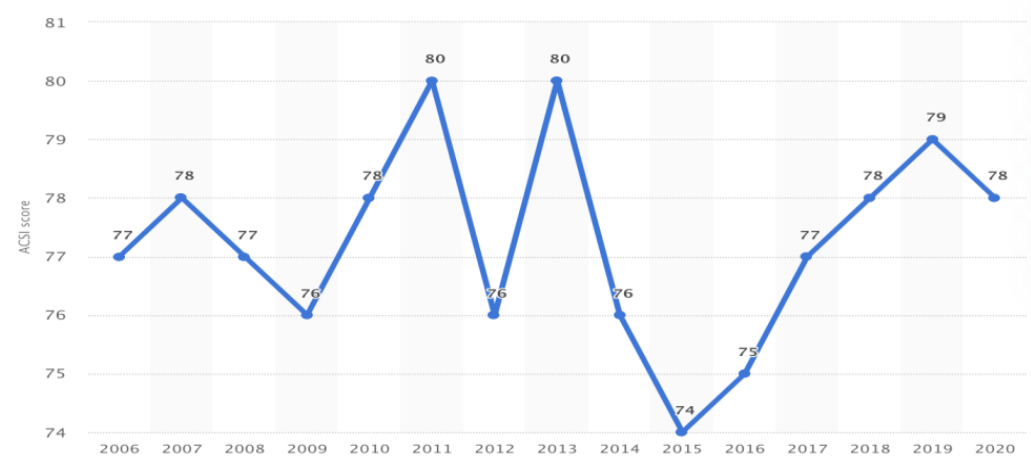

Figure 2: Starbucks' American Customer Satisfaction Index score in the United States, 2006-2020 
In addition, the decline in Starbucks' U.S. Customer Satisfaction Index score in 2020 may be due to closures caused by the outbreak. Customers can't experience the atmosphere in the store as usual.

\section{THE MEASURES TAKEN BY STARBUCKS}

\subsection{Safety}

The spread of the disease has infected some of its employees, requiring isolation and costly medical care. It also scares consumers and affects customer satisfaction. Starbucks has always paid attention to the development of its employees. During the outbreak, it offered employees bonuses, the increase in salary, and promised to pay for their medical expenses. At the same time, Starbucks strictly adheres to hygiene procedures, providing hand sanitizer and temperature measurement in each store, so that employees and customers can work and buy with confidence and Starbucks gains the reputation.

\subsection{Reduced Operating Hours and Foot Traffic}

Starbucks reduced the number of customers in the store and the operating hours, thus reducing the number of people gathered together. The introduction increases the comfort of customers in Starbucks.

\subsection{Temporary Store Closures and Re-openings}

As of Jan. 28, 2020, half of Starbucks stores(4300) in China were temporarily closed. Also, Starbucks plans to close 400 of its stores in North America. Because of China's strict control of the epidemic, more than 90 percent of the shops are now open.[10]

\subsection{Starbucks APP}

Starbucks launched the delivery service which means that customers only need to order in the APP and pay through bank card, Alipay or other payment methods to buy Starbucks products. At the same time, customers can choose grab-and-go, and after placing an order on their mobile phone, they can follow the social distance and in-store regulations to pick up the items quickly. Data from the beginning of March showed that mobile orders in Starbucks China accounted for about $80 \%$ of its sales mix, with $30 \%$ delivery and $50 \%$ online order. [11]

Kevin Johnson(CEO of Starbucks) said, "In every industry, there are periods of disruption that create a great opportunity for those businesses that adapt to the disruption, invest in relevant ways and strengthen their differentiation and competitive advantage." [12]

\section{LUCKIN COFFEE}

Luckin Coffee launched its unmanned retail strategy in January 2020 with the launch of the "Luckin Coffee Express" coffee machine, which will be paired with the existing Luckin store network to further increase its efficiency. It has the following characteristics:

- Easy to operate: support Luckin coffee APP, WeChat small program, Alipay small program to pay orders

- No waiting: 24 hours a day, fresh and ready to go.

- Intelligent cleaning: According to the change of beverage production quantity, machines will intelligently start cleaning system and follow the strict food safety standards[13]

- Coupled with Luckin's free marketing, this combination has great appeal to consumers.

\section{DISCUSSION}

Since the early days of the pandemic, Starbucks has paid close attention to the development and made concrete actions to speed up the recovery. Nick Setyan, an analyst with Wedbush, said he expects Starbucks' revenue to return to pre-Novel Coronavirus levels by 2022, growing at 3 percent to 4 percent a year. [14] Although the Chinese market of Starbucks recovered quickly due to the effective control of the epidemic by the Chinese government, the recovery of the business in the US still needs time and the orderly response to the epidemic, such as vaccines, and so on.

The biggest obstacle to the development of Luckin Coffee is financial fraud. Luckin Coffee admitted on April 2, 2020 that it had fictitious transactions of about 2.2 billion yuan, inflated costs by fictitious raw material procurement, takeout delivery business and other ways, and balance performance and profit data to deceive consumers and investors. Such behavior was strongly condemned, and the State Administration for Market Regulation fined Luckin and its shares fell rapidly. Because that false impression was exposed, Luckin changed its management and agreed to pay $\$ 180$ million to settle with the Securities and Exchange Commission (SEC) in an effort to stay in business. Also, it has made a relatively steady recovery by sharply adjusting discounts and accelerating new product introductions and so on. At present, the company and store operations are struggling to survive since the counterfeiting incident has attracted a lot of attention and doubts about the brand. At the same time, subsidies have been cut to ensure profit margins and new products have been introduced to keep customers fresh. In the future, Luckin needs to make strategies to reduce losses and maintain advantages. It needs to be aware of risk control instead of blindly expanding the market rapidly. 
On April 15, 2021, Luckin Coffee announced that it has secured a $\$ 240$ million investment led by Centurium Capital. Luckin will use the investment to restructure its offshore debt and to satisfy the SEC. This investment can be said to ease Luckin's financial constraints, debt repayment, follow-up recovery and other problems. For at least the next few years, Luckin will still have to adjust its own business and cope with emerging beverage companies.

\section{CONCLUSION}

Although the sales and stock of Starbucks were seriously affected by the epidemic, its rapid and effective measures, as well as its confidence in the brand and products, contributed to its rapid recovery. Luckin coffee's marketing strategy seems to be able to attract funds quickly, but relying on a large number of publicity and discounts to attract consumers for a long time will bring greater losses.

\section{ACKNOWLEDGMENT}

I would like to give my sincere gratitude to all the teachers with extraordinary patience and consistent encouragement by providing me with the advice of great value and inspiration of new ideas.

\section{REFERENCES}

[1] COFFEE MARKET - GROWTH, TRENDS, COVID-19 IMPACT, AND FORECASTS (2021 2026) from

https://www.mordorintelligence.com/industry-repo rts/coffee-market

[2] Development of Starbucks from https://www.starbucks.com

[3] Development of Luckin Coffee from http://www.luckincoffee.com

[4] COVID-19 Has Cost Starbucks \$915 Million So Far, DANNY KLEIN, APRIL 2020 from https://www.qsrmagazine.com/finance/covid-19-ha s-cost-starbucks-915-million-so-far

[5] Starbucks Reports Q1 Fiscal 2020 Results, January 28, 2020 from https://stories.starbucks.com/press/2020/starbucks-r eports-q1-fiscal-2020-results/

[6] Starbucks Reports Q2 Fiscal 2020 Results, April 28, 2020 from

https://stories.starbucks.com/press/2020/starbucks-r eports-q2-fiscal-2020-results/

[7] Starbucks Reports Q3 Fiscal 2020 Results, July 28, 2020 from

https://stories.starbucks.com/press/2020/starbucks-r eports-q3-fiscal-2020-results/

[8] Starbucks Reports Q4 Fiscal 2020 Results, October 29, 2020 from

https://stories.starbucks.com/press/2020/starbucks-r eports-q4-fiscal-2020-results/

[9] Starbucks Reports Q1 Fiscal 2021 Results, January 26, 2021 from

https://stories.starbucks.com/press/2021/starbucks-r eports-q1-fiscal-2021-results/

[10] Coronavirus: Starbucks to close 400 shops and promote 'pickup' concept for pandemic, Jack Dutton, June 11, 2020 from https://www.thenationalnews.com/business/corona virus-starbucks-to-close-400-shops-and-promote-pi ckup-concept-for-pandemic-1.1031917

[11] Letter from Kevin Johnson and Patrick Grismer from https://stories.starbucks.com/uploads/2020/03/Lette r-from-Kevin-Johnson-and-Patrick-Grismer.pdf

[12] How Starbucks is using COVID-19 crisis to differentiate the brand, 2020/8/3 from https://www.warc.cn/newsandopinion/news/how-st arbucks-is-using-covid-19-crisis-to-differentiate-th e-brand/43929

[13] Luckin unmanned retail strategy from http://www.luckincoffee.com/unmanned

[14] The Uncertain Future of Post-Pandemic Starbucks from https://marker.medium.com/the-case-for-shorting-st arbucks-388a91e65421 